\title{
Redação Matemática como instrumento pedagógico
}

\author{
Mathematical Writing as a pedagogical tool
}

\author{
Stelamara Pereira de Souza ${ }^{1}$ \\ Flomar Ambrosina Oliveira Chagas ${ }^{2}$
}

\section{Resumo}

Este produto educacional é resultado de uma pesquisa de dissertação do Programa de Mestrado Profissional do Instituto Federal de Educação, Ciência e Tecnologia de Goiás, Câmpus Jataí, e foi realizado na rede pública estadual e municipal de ensino de Doverlândia-GO. Teve como objetivo desenvolver com docentes do ensino fundamental, na disciplina de Matemática, a leitura e a escrita por meio de histórias em quadrinhos, de carta e de diário utilizando-se as tecnologias digitais no ambiente de aprendizagem Moodle. Foi ministrado um curso de formação de professores com essas ferramentas de apoio, quando os professores elaboraram suas sequências didáticas usando as tecnologias digitais para saber quais os sentidos que os docentes atribuem ao uso da leitura e da escrita Matemática como instrumento pedagógico. Os resultados mostraram que os docentes atribuem diversos sentidos, sendo de ilustração, de complementação, de construção de conceitos e de motivação. Notou-se que a maior dificuldade/desafio em desenvolver atividades com tecnologias digitais se dá pela inexistência e/ou pelas precárias condições dos laboratórios de informática das escolas.

Palavras-chave: Produto educacional. Formação de professores. Redação matemática.

\section{Abstract}

This educational product is the result of a dissertation research of the Professional Master's Program of the Federal Institute of Education, Science and Technology of Goiás, Câmpus Jataí, and was carried out in the public state and municipal public network of Doverlândia-GO. The objective was to develop reading and writing through comics, letter and diary using the digital technologies in the Moodle learning environment with teachers of elementary education in Mathematics. A teacher training course with these support tools was given when the teachers elaborated their didactic sequences using digital technologies to know what the teachers' meanings are attributed to the use of reading and writing Mathematics as a pedagogical tool. The results showed that teachers attribute different meanings, being of illustration, complementation, construction of concepts and motivation. It was noted that the greatest difficulty / challenge in developing activities with digital technologies is due to the inexistence and / or the precarious conditions of the computer labs in the schools.

Keywords: Educational product. Teacher training. Mathematical writing.

\footnotetext{
${ }^{1}$ Mestra em Educação para Ciências e Matemática, professora do Centro Universitário de Mineiros/GO, stelamara@gmail.com

${ }^{2}$ Doutora, professora, Instituto Federal de Goiás/IFG, Câmpus Jataí, flomarchagas@gmail.com
} 


\section{Introdução}

Este produto educacional resultou de uma pesquisa de dissertação do Programa de Mestrado Profissional do Instituto Federal de Educação, Ciência e Tecnologia de Goiás, Câmpus Jataí. O produto foi idealizado com o intuito de se trabalhar a escrita e a leitura na Matemática, usando ferramentas tecnológicas, de modo que pudessem dar aos doze professores participantes, a possibilidade de conhecerem ferramentas tecnológicas e seus usos na prática pedagógica.

Foram convidados todos os professores que ministravam aulas de Matemática no ensino fundamental da cidade e do campo do município de Doverlândia-GO, para participarem de um curso semipresencial, com duração de três meses, sendo um encontro presencial por semana, de maneira que possibilitasse maior participação dos professores. $O$ curso foi ministrado no Laboratório de Informática do Telecentro Municipal e no primeiro encontro foi esclarecido que se tratava de uma pesquisa/produto. Foram entregues aos cursistas os termos de consentimento, foi dito sobre o formato do curso, carga horária de 120 horas, além de abordagem teórica e prática quanto à temática, pois para Brzezinski (2008) a preparação docente deve visar entre outros, ao saber pedagógico das tecnologias, refletindo sobre o seu uso no ambiente educacional.

A opção pelo curso semipresencial foi para incentivar os docentes a participarem, visto que eles tinham cargas horárias elevadas. Conforme Borges (2005), a modalidade de educação semipresencial é destacada como sendo também uma modalidade híbrida de educação, na qual essa hibridação significa a (re)elaboração da modalidade de educação presencial com novos métodos e novas concepções educacionais. Desta forma, os docentes tinham a oportunidade de interagir com colegas e com as pesquisadoras sempre antes do próximo encontro presencial.

O produto foi sendo construído à medida que os encontros aconteciam. As atividades foram planejadas de maneira que os encontros fossem mais produtivo 
possível. Assim, era possível compreender a realidade dos docentes participantes na construção do material para os próximos encontros.

Durante as atividades, os professores foram orientados a desenvolver uma sequência didática em sua turma, discuti-la nos encontros presenciais para, em seguida, aplicá-la com seus alunos, envolvendo as ferramentas tecnológicas como apoio pedagógico, no caso das Histórias em Quadrinhos (HQ), o software HagáQuê. E após a aplicação da sequência, os professores retornariam aos encontros com os resultados obtidos para discussão e para troca de experiências.

Os docentes tiveram, assim, a oportunidade de produzir suas próprias sequências didáticas utilizando $\mathrm{HQ}$, cartas e diários, e verificar a possibilidade de esses recursos serem usados para ministrarem os conteúdos desenvolvidos. Dessa forma, os professores se sentiram motivados a discutirem problemas matemáticos tratados em sala de aula e a interligarem seus conhecimentos matemáticos com o cotidiano nas produções. Faria (1998, p. 17) afirma que "quando o aluno faz uma Redação em Matemática, ele demonstra o que aprendeu e permite ao professor avaliar as ideias apresentadas, dando a eles a importante oportunidade de avaliar a aprendizagem e o seu ensino, respectivamente".

O objetivo foi usar a leitura e a escrita ( $\mathrm{HQ}$, carta e diário) na disciplina de Matemática, por meio das Tecnologias Digitais (TD). Desse modo, o curso possibilitou compreender as dificuldades ou não dos professores ao utilizar os computadores, quando os laboratórios de informática se tornavam espaços que, às vezes, assumiam outras finalidades, como sala de vídeo e sala de projeção, além de tirar dúvidas, de promover o estímulo com o uso das ferramentas tecnológicas e, ainda, investigar qual o sentido que os docentes atribuiriam à escrita na disciplina de Matemática.

Assim sendo, buscou respostas as questões: quais os sentidos que os docentes atribuem ao uso da leitura e da escrita em Matemática como instrumento pedagógico? Como o uso de escrita Matemática com TD podem contribuir para a aprendizagem Matemática? 
Diante das dificuldades apresentadas pelos alunos do ensino fundamental no processo de ensino aprendizagem da Matemática em relação à compreensão dos conteúdos por, muitas vezes, serem apresentados de maneira formalizada, sem contextualização, destaca-se, assim, os motivos que justificam o porquê de se trabalhar com a escrita na Matemática na formação continuada de professores.

Para D’Ambrósio (2012), a educação formal é, na maioria das vezes, baseada na mera transmissão de explicações ou na prática de exercícios repetitivos que acabam tornando equivocadas. $\mathrm{O}$ autor destaca ainda que "o grande desafio que se encontra na educação é justamente sermos capazes de interpretar as capacidades e a própria ação cognitiva não da forma linear, estável e contínua que caracteriza as práticas educacionais mais correntes", (D'AMBROSIO, 2012, p. 109). Desta forma, é necessário que se tenha um outro cenário na sala de aula, em que o professor seja capaz de inserir novos instrumentos pedagógicos permitindo aos alunos se envolverem com a Matemática, dando significado aos conteúdos estudados. Como afirma Pais (2013, p. 75) "é preciso valorizar estratégias de ensino que envolvam diferentes linguagens e não priorizar a dimensão abstrata dos conceitos.

A construção deste produto educacional foi proveitoso, visto que os docentes se sentiram motivados a desenvolver atividades de Matemática utilizando esses recursos de aprendizagem, ao desenvolver com os alunos a construção de histórias em quadrinhos, a elaboração de cartas e o registro em diários, e ao enfatizar os conhecimentos matemáticos por meio da leitura e da escrita.

\section{Produto Educacional - história em quadrinhos, cartas e diários}

\subsection{Aporte teórico}

Valente (1999), afirma que, em meados da década de 50, os computadores começaram a ser inseridos na educação, mas que naquela época, a ênfase era 
de armazenar informações em uma sequência e então transmitir ao aprendiz. $E$ que na segunda década do século XXI, a realidade é bem diversificada, quando os docentes têm inúmeras possibilidades de inserir essa ferramenta no contexto educacional.

O uso de softwares, da internet, de mídias nas escolas, tem sido muito discutido em encontros educacionais, formando um outro contexto que, para Miskulin (2003), é nova cultura profissional, novas linguagens se configuram exigindo formação continuada. Para esta autora, as tecnologias estão presentes nos mais diversos setores da sociedade; assim, é imprescindível engajar e discutir criticamente essa disseminação dos computadores na sala de aula, para que se criem ambientes compatíveis com o desenvolvimento tecnológico. E na Educação Matemática, essa contextualização vem sendo discutida em pesquisas envolvendo as tecnologias.

Como reforça Miskulin (2003, p. 7)

A Tecnologia não consiste apenas em um recurso a mais para os professores motivarem as suas aulas, consiste, sobretudo em um meio poderoso que pode propiciar aos alunos novas formas de gerarem e disseminarem o conhecimento, e, consequentemente, propiciar uma formação condizente com os anseios da sociedade. Assim sendo, os professores de Matemática devem refletir sobre a sua utilização, trabalhando em pesquisas que implementem projetos nas escolas, Design de ambientes interativos de aprendizagem colaborativa - que possam oferecer oportunidades para que os seus alunos aprendam Matemática e ao mesmo tempo, utilizem a Tecnologia de forma que a Matemática, no contexto tecnológico, torne-se um caminho que possa superar as desigualdades sociais e ainda possibilitar a formação e a inserção adequada do sujeito a uma sociedade permeada pela tecnologia.

D’Ambrósio (2012, p.74) afirma que "informática e comunicações dominarão a tecnologia educativa do futuro" e, dessa forma, o professor precisa rever o seu papel como docente, refletindo questões de como ensinar na contemporaneidade, de como inserir essas ferramentas na prática pedagógica. Além disso, o autor ressalta que "será essencial para a escola estimular a aquisição, a organização, a geração e a difusão do conhecimento integrado nos valores e nas expectativas da sociedade. Isso será impossível de atingir sem a ampla utilização da tecnologia na educação". Assim, deve-se envolver as novas tecnologias na aula de Matemática, levando discentes e docentes a novas 
alternativas no ensinar e no aprender. É importante refletir sobre o uso do aparato tecnológico na escola.

Como afirma Libâneo (2011, p. 29),

É fundamental que o novo professor seja aquele capaz de ajustar sua didática às novas realidades da sociedade, do conhecimento, do aluno, dos meios de comunicação. O novo professor precisaria, no mínimo, de adquirir sólida cultura geral, competência para saber agir na sala de aula, habilidades comunicativas, domínio da linguagem informacional e dos meios de informação, habilidade de articular as aulas com as mídias e multimídias.

O produto educacional teve um enfoque na leitura e na escrita na disciplina de Matemática, tendo como principal suporte teórico Nacarato e Lopes (2009, p.44), os quais destacam que a escrita "dá indícios de como os alunos pensam e produzem Matemática na sala de aula e de como os professores trabalham e mobilizam seus saberes profissionais". Percepções de outros teóricos também fortalecem essa pesquisa ao envolver os docentes no mundo da leitura e da escrita na Matemática. Ponte, Oliveira e Varandas (2001) afirmam que para o ensino ser inovador, é necessário oportunizar aos alunos novos desafios, criar, estimular e diversificar a prática pedagógica. Assim, esse produto educacional possibilitou a oportunidade dos docentes ampliar os conhecimentos pedagógicos.

\subsection{Passos metodológicos}

Este produto é parte de uma pesquisa de abordagem qualitativa e fez uso dos princípios da pesquisa-ação. De acordo com Triviños (2012), a pesquisa qualitativa tem ambiente natural como fonte direta dos dados e o pesquisador ou pesquisadora como instrumento-chave; é descritiva, preocupa com o processo e não simplesmente com os resultados e o produto, tende analisar os dados indutivamente e o significado é a preocupação essencial. Para Moreira e Caleffe (2008, p. 92), pesquisa-ação no ambiente escolar é um meio de:

a) de sanar os problemas diagnosticados em situações específicas, b) [...] proporcionando ao professor novas habilidades, métodos para aprimorar sua capacidade analítica e o fortalecimento da autoconsciência; c) de introduzir abordagens adicionais e inovadoras no processo ensino-aprendizagem e aprender continuamente em um sistema que normalmente inibe a mudança e a inovação; [...] 
O objetivo deste produto foi desenvolver um curso com docentes do ensino fundamental que envolvesse a leitura e a escrita em Matemática por meio de histórias em quadrinhos (HQ), carta e diário utilizando-se das TD no ambiente de aprendizagem Moodle. Ministrou-se a modalidade $\mathrm{HQ}$ por meio do software HagáQuê, foram apresentadas as ferramentas que o software oferece e a modalidade carta e diário, utilizando-se do computador para redigir os textos. Os professores conheceram essas modalidades por meio das oficinas oferecidas no curso.

Este produto educacional se destina principalmente a professores de Matemática do $1^{\circ}$ ao $9^{\circ}$ ano do ensino fundamental, consta de planos de unidade, tutorial plataforma moodle, tutorial Google drive tutorial hagáquê, as sequências didáticas das $H Q$, das cartas e dos diários.

Os planos de unidades contêm: o público alvo, o período de realização, se presencial ou à distância, o assunto/conteúdo, os objetivos, os procedimentos, as sugestões de leituras e os recursos utilizados. O tutorial plataforma Moodle traz informações sobre Ambiente virtual Moodle (Modular Object-Oriented Dynamic Learning Environment) e os primeiros passos para acessar a plataforma Moodle, e como se inscrever nele. O Tutorial Google Drive traz informações sobre serviço de armazenamento de arquivos. O tutorial Hagáquê apresenta informações sobre este software educativo, que permite explorar a linguagem escrita, e possui um banco de imagens, com cenários, personagens, além de outros recursos que possibilitam o aluno a usar sua imaginação em diversas áreas do conhecimento. Este tutorial foi desenvolvido de modo a facilitar a criação das Histórias em Quadrinhos, auxiliando o professor no processo de ensino aprendizagem e de como instalá-lo e os passos de como acessá-lo.

Por meio das categorias de análise buscou-se compreender as concepções que os professores apresentaram nas sequências didáticas sobre histórias em quadrinhos, cartas e diários. Para isso, foi necessário investigar: quando o sentido de ilustração passa a ser significativo no contexto da Educação Infantil e do ensino fundamental? Os docentes aplicaram suas sequências didáticas no 
sentido de complementação de um conteúdo já abordado ou complementou esse conteúdo utilizando-se da interdisciplinaridade? Houve construção de conceitos ao elaborar a sequência didática provocando o aluno para se expandir na escrita na Matemática? O docente trabalhou a Matemática com atividades motivacionais? Utilizar a produção escrita da Matemática com a tecnologia digital permitiu compreender diversos aspectos, principalmente quando diz respeito à utilização das tecnologias no ensino. Afirma Miskulin (2003) que, com o avanço da Ciência e da Tecnologia, é preciso incentivar e explorar a prática educativa tecnológica, de forma consciente e crítica, criando cenários interativos de aprendizagem.

\subsection{Análise das sequências didáticas}

A partir da categorização foi realizada a análise das sequências didáticas elaboradas pelos professores no curso com HQ, com cartas e diários. Em relação ao recurso $H Q$, identificou-se que $34 \%$ das sequências apresentaram características de complementação de conteúdo, quando os docentes abordavam conteúdos já trabalhados. Assim, o recurso $H Q$ completou o que já havia estudado, utilizando conceitos matemáticos até mesmo para complementar outras disciplinas. E $33 \%$ das sequências se enquadraram na categoria motivação, pois de acordo com os professores, é um recurso interessante, atrativo, que os alunos gostaram e que thes possibilitaram o aprendizado. Outras dezenove por cento eram voltadas para ilustração. Foi notório, principalmente quando o docente inseriu o uso dos gibis para leitura, representações, materiais concretos e imagens.

Por fim, 14\% dos sujeitos destacaram a construção de conceitos, em que os conhecimentos matemáticos foram inseridos, a partir dos conhecimentos do discente. Vale ressaltar que houve sequências que apresentaram todas as características das categorias estabelecidas. $\mathrm{O}$ resultado aponta que as sequências didáticas, neste caso, distanciam-se da formação de conceitos, dando mais ênfase à complementação ao conteúdo e à motivação. 
$\mathrm{Na}$ análise das sequências referentes ao recurso carta e diário, notou-se que $31 \%$ delas apresentaram o sentido de complementação, nesse caso, muitos professores preferiram revisar conteúdos e explorar a produção de textos descritivos, seguida de $30 \%$ daqueles que abordaram o sentido de motivação. Foram destacadas, principalmente as sequências didáticas realizadas no ensino fundamental I, com $22 \%$ de ilustração, quando os docentes incentivaram as produções de cartas e de diários para construção de desenhos, de formas geométricas, de gráficos e de tabelas. Dezessete por cento abordaram a construção de conceitos, quando incluíram diversos métodos para compreensão dos significados matemáticos.

Nessa perspectiva, o curso aplicado aos docentes tornou-se um desafio para as pesquisadoras mediante o desenvolvimento dele. Ao envolver as TD como possibilidade de ensino num curso de formação, observou-se, desde o início, que as barreiras seriam desafiadoras, para tanto era necessário compreender os aspectos envolvidos. Assim, já no primeiro encontro do curso, ao realizar a oficina com os professores do ambiente virtual de aprendizagem Moodle, percebeu-se que a capacidade da internet nos computadores do Telecentro municipal era insuficiente para o curso. Por essa razão, as pesquisadoras tiveram que custear por conta própria os gastos com a capacidade dos computadores.

Os participantes consideram importante utilizar essas ferramentas como recurso pedagógico, mas poucos professores tinham o hábito de utilizá-las em suas aulas, pela falta de infraestrutura das escolas ou domínio próprio como se pode notar ao serem entrevistados:

P1: "O laboratório da minha escola não está em funcionamento devido à falta de peça dos computadores, às vezes, em que o utilizei foi somente para apresentações de slides".

P2: "Não utilizo por não ter domínio satisfatório da informática e o laboratório quase sempre não oferece condições adequadas para serem usados". 
P3: "Não utilizo com frequência porque o laboratório está com softwares defasados e os computadores em péssimas condições".

P4: "[...] Barra na burocracia de laboratórios sucateados, e sem manutenção adequada, na falta de preparo adequado do professor ou de profissionais da educação que vem lidar com essas máquinas ou com os softwares existentes nelas e também na falta de suporte técnico para os professores; com isso o planejamento do professor perde o teor principal que é levar o aluno a compreender o que está construindo, levando-o apenas a ser um espectador do que está sendo transmitido e, às vezes, o próprio professor é um mero transmissor do que Ihe foi transmitido por outra pessoa, em supostas capacitações. Com isso, os laboratórios que ainda existem estão mais sendo usados como sala de vídeo do que como ambiente de construção do conhecimento".

Com base no fórum dos participantes, é preciso destacar dois pontos: a importância de formação continuada dos professores nas escolas públicas para que envolvam as tecnologias em suas aulas e a falta de infraestrutura no Laboratório de Informática Educacional que acaba gerando um cenário negativo para desenvolver atividades envolvendo as TD. E para isso, é necessário investimento, políticas públicas para capacitação de profissionais da educação e condições necessárias aos docentes para que possam inserir atividades com as TD no planejamento de aulas.

Para os professores participantes, o software Hagáquê foi um recurso que contemplou as expectativas de aprendizagem em sala de aula. Em seus relatos há o desejo de trabalhar o recurso, mas eles afirmaram precisar de tempo para desenvolver as atividades, de dedicação do professor em promover conhecimento matemático por meio da leitura e da escrita e de infraestrutura suficiente nos laboratórios de informática. Como ressaltam Nacarato e Lopes (2009), o ato de escrever requer tempo e prática, e exige do professor mudança de atitude para aprender a ouvir seus alunos, dar retorno constante nas produções escritas. $\mathrm{Na}$ figura 1, exemplifica um dos trabalhos de professores desenvolvido no curso. 

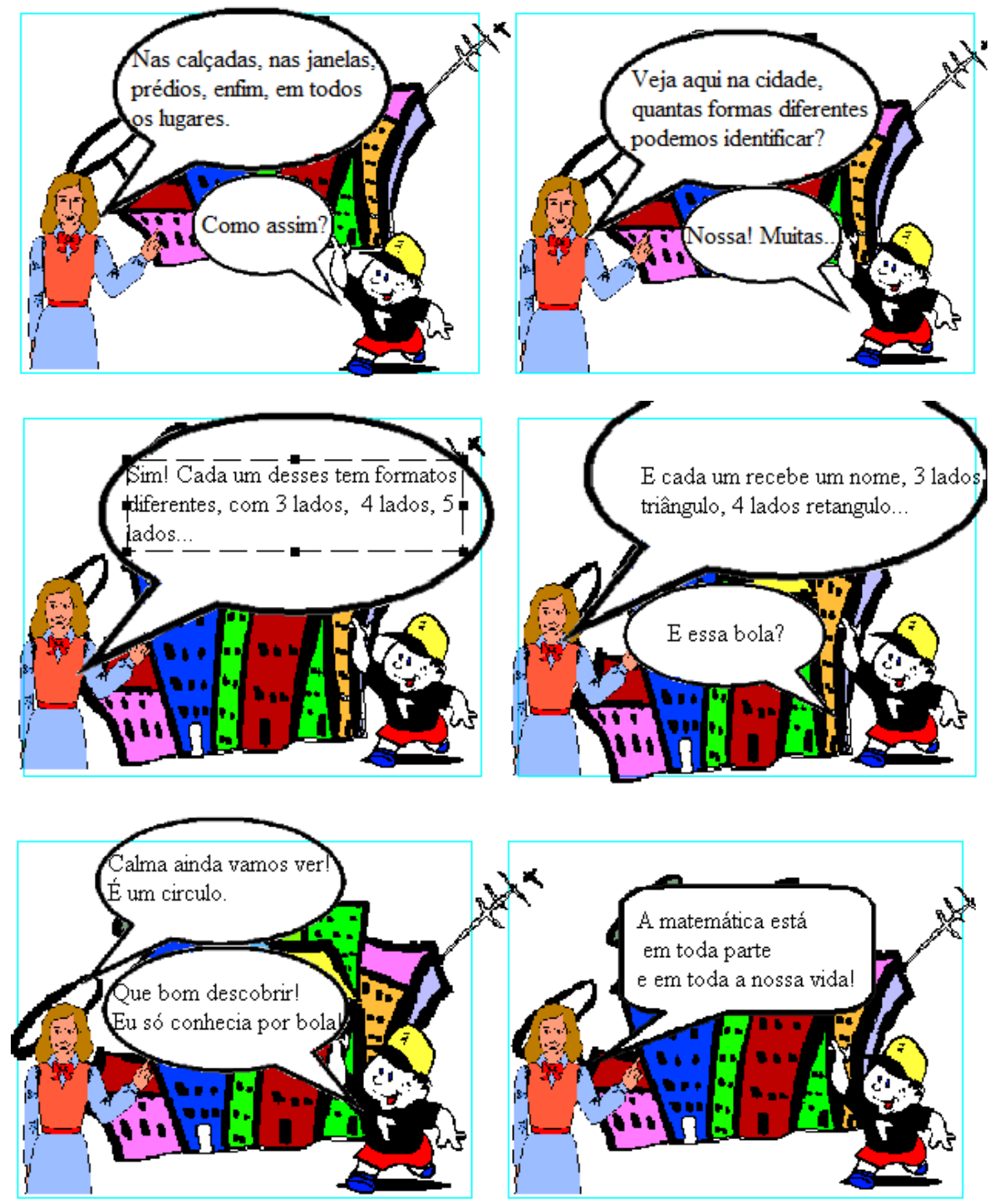

Figura 1: HQ produzida por professores durante o curso de formação com o tema Geometria/Estudo das formas.

Quanto ao uso das cartas, professores participantes afirmaram ser necessário fazer um roteiro manuscrito, assim como as $\mathrm{HQ}$, na escrita de cartas, para posteriormente utilizar as ferramentas tecnológicas. Revela-se, assim, ser um recurso fácil de trabalhar e motivador para os alunos. 58\% dos participantes consideraram que os alunos não dominam a escrita. As dificuldades dos alunos em escrever existem, mas cabe ao docente incentivar a leitura e a escrita em todas as disciplinas; não é uma obrigação somente do professor de Língua 
Portuguesa produzir e corrigir textos, mas sim de todos docentes. Na resolução de problemas matemáticos, na construção dos conceitos, no letramento matemático, na simbologia Matemática e na produção de significados é essencial expandir essa ideia de ler e escrever. Smole e Diniz (2007) afirmam que, muitas vezes, os alunos encontram obstáculos na resolução de problemas por não compreenderem os significados matemáticos.

Quanto ao diário, os docentes avaliaram também que os alunos não tinham domínio da escrita, mas a percentagem é menor referente à produção de cartas, ao que os professores justificaram afirmando que as discentes já tinham o hábito de escrever diários pessoais, o que é diferente dos discentes.

Quando foi proposto que os docentes utilizassem as TD, apenas um deles diferenciou sua prática utilizando o celular. Os demais utilizaram o editor de texto conhecido Word. Assim, é importante ressaltar que trabalhar com a leitura e a escrita Matemática permitiu ao professor vivenciar a sua prática, ponderando quais práticas permaneciam e quais seriam modificadas num próximo trabalho. As dificuldades enfrentadas pelos docentes serviram para reflexão, assim como afirmam Barbosa, Nacarato e Penha (2008, p. 84), "quando os alunos começam a escrever seus textos, estes podem não explicitar o aprendizado matemático; as mudanças acontecem com o passar do tempo e com a prática constante da escrita, que propicia a reflexão". Por essa razão, acredita-se que o curso foi um veículo de inserção desses instrumentos nas práticas dos docentes participantes.

Dos doze participantes, $87 \%$ afirmaram que há Laboratório de Informática Educacional (LIE) nas escolas em que trabalham, mas com poucas condições de uso, problemas com conexão com a internet, falta de manutenção das peças e até mesmo a inexistência deles para executar suas atividades. Assim, há uma quantidade mínima de professores que utilizam as TIC como recursos pedagógicos, ferramentas tecnológicas na disciplina de Matemática.

O investimento em políticas públicas é fundamental para que se deem condições dos professores participem de cursos de formação inicial e continuada 
no ensino de Matemática, como este curso componente do produto educacional construído com $\mathrm{HQ}$, cartas e diários usando as TD.

Os encontros à distância foram realizados pelo ambiente virtual de aprendizagem Moodle e, por meio dele, as pesquisadoras acompanharam todo o processo de formação e moderaram as atividades dos professores participantes.

\section{Considerações finais}

Este produto educacional, resultado de uma pesquisa de mestrado, foi desenvolvido com professores da rede pública de ensino a fim de contribuir com a prática pedagógica do professor de Matemática. O curso e sua aplicação está disponível no link: http://redmatematica.webnode.com//, para que outros docentes possam utilizá-los, adaptando a diversos segmentos educacionais.

O professor vive enorme dilema, urge se adequar ferramentas tecnológicas em suas aulas, mas, ao mesmo tempo, encontra inúmeras barreiras para desenvolver atividades envolvendo as TD. Os dados apresentados nessa pesquisa mostram essa dualidade da relação professor-computador. Por um lado, há professores interessados em usar as tecnologias em sala de aula, por outro, há falta de infraestrutura básica necessária para realizar atividade com as TD. Contradizendo, assim, os escritos de Borba e de Penteado (2012) ao afirmar que os estudantes das escolas públicas e particulares devem ter no mínimo alfabetização tecnológica, direito ao acesso a ela, uma vez que o computador deve ser inserido em atividades essenciais, sendo preciso aprender a ler essa nova linguagem.

$\mathrm{Na}$ construção deste produto, os professores puderam analisar, refletir, trocar experiências, avaliar a sua prática pedagógica e visualizar outros recursos educacionais capazes de proporcionar o conhecimento matemático, por meio das TD, ferramentas importantes no desenvolvimento de suas propostas didáticas nas aulas de Matemática. 
Dificuldades surgiram como, por exemplo, carga horária excessiva dos professores, como o deslocamento dos que moravam no campo para a cidade, a falta de infraestrutura das instituições escolares.

Nos momentos presenciais, os professores expressavam como os conhecimentos matemáticos eram inseridos na escrita das histórias em quadrinhos, da carta e do diário, o que possibilitou compreender os sentidos que eles atribuíam ao uso da redação Matemática. Desmitificando, assim, a ideia de que a leitura e a escrita são de responsabilidade do professor de Língua Portuguesa.

A investigação dos sentidos que os professores atribuíram aos recursos educacionais $\mathrm{HQ}$, carta e diário, possibilitou compreender aqueles docentes que demonstraram uma visão de construção dos conceitos matemáticos, aqueles que demonstraram os sentidos de motivar o aluno, também de desenvolver as atividades por meio de ilustrações, tanto manuais quanto digitais e ainda os que apresentaram 0 sentido de complementação, utilizando atividades interdisciplinares e inserindo conteúdos trabalhados em sala de aula.

Desse modo, os resultados mostraram que nas sequências didáticas utilizando $\mathrm{HQ}$ destacou-se o uso das ilustrações para expressar conhecimentos matemáticos; e nas sequências didáticas, com os recursos educacionais carta e diário notou-se que, além de o docente resgatar a cultura da carta, dos registros nos diários, foi Ihes possível discutir a importância desses instrumentos como prática de auto-avaliação e de expressão dos sentimentos na manifestação dos conhecimentos.

O processo de desenvolvimento da escrita na Matemática com as TD constituíram ferramentas de múltiplas possibilidades. Contribuíram para auxiliar os desenhos na construção no software HagáQuê, a diversificar as cartas e os diários, na aprendizagem Matemática. O desenvolvimento do curso com os docentes trouxe elementos fundamentais, pois eles demonstraram interesse em retomar as atividades com outras turmas; compreenderam a necessidade de 
inserir a leitura e a escrita nas aulas de Matemática e perceberam a importância de superar as dificuldades quanto às TD.

Mesmo diante das limitações em realizar um curso semipresencial, utilizando um ambiente virtual de aprendizagem que, já no primeiro encontro, demonstrou ser impossível conectar as máquinas com pouca velocidade da internet. Entretanto, nem isso deixou de ser um obstáculo para realizar a pesquisa, daí a importância de enfrentar os desafios previsíveis que se configuram na prática pedagógica. Assim, sugere-se ao docente que faça uso desse produto educacional, incentivando seus alunos à prática da leitura e da escrita na disciplina que ministra, mesmo não havendo possibilidades de inserir as TD como foi proposto nesse curso, que busquem alternativas para ler e redigir textos matemáticos, desenvolvendo a aprendizagem, consequentemente, possibilita a inserção do educando na sociedade tecnológica, aguçando neles a criticidade e disseminando conhecimento.

\section{Referências}

BARBOSA, Kelly C. Betereli A.; NACARATO, Adair Mendes; PENHA, Paulo César da. A escrita nas aulas de Matemática revelando crenças e produção de significados pelos alunos. Série-estudos, Campo Grande, MS, v. 1, n. 26, p.79-95, jul. 2008.

BORBA, Marcelo de Carvalho; ARAÚJO, Jussara de Loiola (Org.). Pesquisa Qualitativa em Educação Matemática. Belo Horizonte: Autêntica, 2013.

BORBA, Marcelo de Carvalho; PENTEADO, Miriam Godoy. Informática e Educação Matemática. 5. ed. Belo Horizonte: Autêntica, 2012.

BORGES, Martha Kaschny. Educação Semipresencial: desmistificando a Educação a Distância. ABED, Maio/2005. Disponível em: Acesso em:21. fev. 2015.

BRZEZINSKI, Iria. Políticas contemporâneas de formação de professores para os anos iniciais do ensino fundamental. Educação \& Sociedade, Campinas, v. 29, n. 105, p.1139- 1166, set. 2008.

D'AMBROSIO, Ubiratan. Educação Matemática: da teoria à prática. 23. ed. Campinas, SP: Papirus, 2012. 
FARIA, Celso de Oliveira. Redação Matemática: A comunicação como mediadora na formação de conceitos matemáticos. Interação. Revista da Faculdade de Educação, Goiânia: UFG, v.22. n.1/2, 1998.

LIBÂNEO, José Carlos. Adeus professor, adeus professora?: novas exigências educacionais e profissão docente. 2. ed. São Paulo: Cortez, 2011

MISKULIN, Rosana Giaretta Sguerra. As possibilidades didático-pedagógicas de ambientes computacionais na formação colaborativa de professores de Matemática. In: FIORENTINI, Dario (Org.). Formação de Professores de Matemática: Explorando Novos Caminhos com outros Olhares. Campinas: Mercado das Letras, 2003. p. 1-26. Disponível em: . Acesso em: 06 jan. 2015.

MOREIRA, Herivelto; CALEFFE, Luiz Gonzaga. Metodologia da pesquisa para o professor pesquisador. 2. ed. Rio de Janeiro: Lamparina, 2008.

NACARATO, Adair Mendes; LOPES, Celi Espasandin. Práticas de leitura e escrita em educação Matemática: tendências e perspectivas a partir do seminário de educação Matemática no Cole. In: LOPES, Celi Espasandin; NACARATO, Adair Mendes (Org.). Educação Matemática, leitura e escrita: armadilhas, utopias e realidade. Campinas, Sp: Mercado de Letras, 2009. p. 25-46.

PAIS, Luis Carlos. Ensinar e aprender Matemática. 2. ed. Belo Horizonte: Autêntica, 2013.

PONTE, João Pedro da; OLIVEIRA, Hélia; VARANDAS, José Manoel. O contributo das tecnologias de informação e comunicação para o desenvolvimento do conhecimento e da identidade profissional. 2001. Disponível em: Acesso em: 12 jan. 2015.

TRIVIÑOS, Augusto Nibaldo Silva. Introdução á pesquisa em ciências sociais: a pesquisa qualitativa em educação. São Paulo: Atlas, 2012.

VALENTE, José Armando. Informática na educação no Brasil: análise e contextualização histórica. In: VALENTE, José Armando (Org.). O computador na sociedade do conhecimento. Campinas, SP: Nied, 1999. p. 1-13. 